ARTICLE

Received 24 Jul 2014 | Accepted 10 Sep 2014 | Published 10 Oct $2014 \quad$ DOI: 10.1038/ncomms6225

\title{
The mediator subunit Med23 contributes to controlling T-cell activation and prevents autoimmunity
}

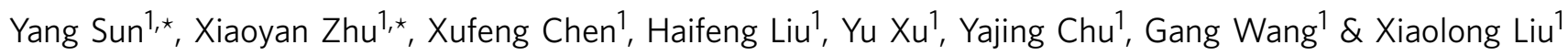

T-cell activation is critical for successful immune responses and is controlled at multiple levels. Although many changes of T-cell receptor-associated signalling molecules affect T-cell activation, the transcriptional mechanisms that control this process remain largely unknown. Here we find that $T$ cell-specific deletion of the mediator subunit Med23 leads to hyperactivation of T cells and aged Med23-deficient mice exhibit an autoimmune syndrome. Med23 specifically and consistently promotes the transcription of multiple negative regulators of T-cell activation. In the absence of Med23, the T-cell activation threshold is lower, which results in enhanced antitumour T-cell function. Cumulatively, our data suggest that Med23 contributes to controlling T-cell activation at the transcriptional level and prevents the development of autoimmunity.

\footnotetext{
${ }^{1}$ State Key Laboratory of Cell Biology, Institute of Biochemistry and Cell Biology, Shanghai Institutes for Biological Sciences, Chinese Academy of Sciences, Shanghai 200031, China. * These authors contributed equally to this work. Correspondence and requests for materials should be addressed to G.W. (email: gwang@sibcb.ac.cn) or to X.L. (email: liux@sibs.ac.cn).
} 
T cells play pivotal roles in adaptive immunity. Optimal T-cell activation requires T-cell receptor (TCR) signalling on binding to the peptide-MHC complex on the antigenpresenting cell (APC) and CD28 costimulatory receptor engagement as a second signal ${ }^{1}$. The induction of surface molecules, such as CD25, CD44 and CD69, constitute an early event during T-cell activation that is accompanied by the production of multiple cytokines, such as interleukin 2 (IL-2), interferon $\gamma$ (IFN $\gamma$ ) and so $\mathrm{on}^{2}$. Cellular activation is a threshold-based phenomenon, and the T-cell activation threshold represents the minimum overall stimulation generated at the T cell-APC interface required to elicit a response ${ }^{3}$. Since stimulation strength is biologically a very complex entity, it was abstractly represented as a single parameter called 'excitation', and the threshold was postulated to emerge from certain generic kinetic characteristics of the interplay of excitation and 'deexcitation'3. The latter, representing the action of negative regulators that counter the effects of excitation (for example, through dephosphorylation or protein degradation) have now been shown to be present in abundance at various levels of signal transduction $^{4-8}$.

Signals from several triggered TCRs are integrated downstream $^{9}$, which activate multiple effector pathways to determine whether cells become activated or desensitized. Much of the work on TCR signalling and T-cell activation has been focused on positive regulators ${ }^{10-13}$; however, more attention has been paid to negative regulators of $\mathrm{T}$-cell activation from the cell surface to the nucleus in recent years ${ }^{14}$. For example, CD45 and SH2 domaincontaining phosphatase-1 dephosphorylate lymphocyte-specific protein tyrosine kinase, resulting in the cessation of TCR signal $^{5,6}$. E3 ubiquitin-protein ligase $\mathrm{Cbl}$ family proteins negatively regulate $\mathrm{T}$-cell activation by facilitating the ubiquitination and degradation of proteins ${ }^{7,8}$. Inhibitory signals from coreceptors, such as cytotoxic T lymphocyte antigen-4 and programmed death-1, limit T-cell activation, which have documented the significance for maintaining self-tolerance ${ }^{15-17}$. Moreover, regulatory T cells (Treg) have been proved to suppress T-cell activation directly or by inhibiting the activation status of $\mathrm{APCs}^{18}$. Importantly, alterations in these regulators have been shown to play important roles in the initiation of autoimmune disorders ${ }^{4,19,20}$. Together, the function and mechanisms of TCR signalling events in T-cell activation have been extensively investigated. However, it remains largely unknown how T-cell activation is controlled at the transcriptional level.

The mammalian mediator complex is an evolutionarily conserved multiprotein complex composed of more than 20 subunits. This complex functions as a molecular bridge between gene-specific transactivators and the RNA polymerase II-associated basal transcription machinery ${ }^{21,22}$. This mediator complex also functions as an integrative hub for channelling different signalling pathways ${ }^{23}$. Although the mediator complex seems to be universally required for the transcription of all genes, specific subunits are dedicated to the regulation of distinct expression programmes by interactions with relevant genespecific transcriptional activators ${ }^{22}$. Recently, the mediator subunit Med23 (also known as Sur2) has attracted attention because it regulates the mitogen-activated protein kinase signalling pathway ${ }^{24,25}$. Med23 mediates the immediate early gene (IEG) response to serum mitogens, which is required for mediator recruitment to a small subset of genes that are predominantly controlled by the mitogen-activated protein kinase signalling pathway ${ }^{24,25}$. Moreover, Med23 has important roles in diverse biological processes including adipogenesis, brain development, cell differentiation and carcinogenesis ${ }^{26-29}$.

Here we identify Med23 as a bona fide factor that contributes to controlling T-cell activation and prevents the development of autoimmunity. Med23 deficiency leads to T-cell hyperactivation, and aged Med23-deficient mice exhibit an autoimmune syndrome. In particular, Med23-deficient $\mathrm{T}$ cells are hyperresponsive to TCR stimulation and exhibit enhanced antitumour function. We further demonstrate that Med23 selectively promotes the transcription of multiple negative regulators of T-cell activation. Taken together, our data suggest that Med23 plays important roles in controlling T-cell activation to maintain T-cell tolerance to self-antigens.

\section{Results}

Med23 deficiency leads to reduced numbers of $T$ cells. To investigate the functions of Med23 in T cells, Med23 conditional knockout $\left(\operatorname{Med} 23^{-1-}\right)$ mice were generated by breeding mice with loxP-flanked Med23 alleles (Med $23^{\mathrm{fl} / \mathrm{fl}}$ ) (ref. 28) and CD4 promoter-cre transgenic mice. This breeding resulted in specific deletion of Med23 by the double-positive stage of T-cell development. Med23 was efficiently deleted in mature thymocytes and peripheral $\mathrm{T}$ cells, based on the analysis of mRNA and protein levels (Supplementary Fig. 1a,b). The expression of the surface markers CD5, CD69, TCR $\beta$ and HSA was similar between $\mathrm{Med} 23^{-/-}\left(\mathrm{Cd} 4 \mathrm{Cre}^{+} \mathrm{Med} 23^{\mathrm{fl} / \mathrm{fl}}\right)$ and wild-type (WT, Cd4Cre ${ }^{-} M e d 23^{\mathrm{fl} / \mathrm{fl}}$ or $\mathrm{Cd} 4 \mathrm{Cre}^{-} \mathrm{Med} 23^{+/ \mathrm{fl}}$ ) thymocytes (Supplementary Fig. 1c,d). In addition, Med $23^{-1-}$ mice showed similar cell numbers of various $\mathrm{T}$-cell subsets in the thymus (Fig. 1a,b) compared with WT mice. However, Med $23^{-1-}$ mice had fewer $\mathrm{CD}^{+}{ }^{+}$and $\mathrm{CD}^{+}{ }^{+} \mathrm{T}$ cells in the periphery compared with WT mice (Fig. 1c-f). Because the number of peripheral $\mathrm{T}$ cells is maintained predominantly by cell proliferation and survival ${ }^{30}$, we next assessed T-cell proliferation and survival in the absence of Med23. Med $23^{-1-}$ mice demonstrated the same percentage of cycling cells as WT mice (Fig. 1g) although Med $23^{-I^{-}}$mice showed increased T-cell apoptosis and death (Fig. 1h,i). Presumably, the reduced number of peripheral $\mathrm{T}$ cells in Med $23^{-1-}$ mice resulted from increased T-cell death.

$\mathrm{T}$ cells are hyperactivated in the absence of Med23. Intriguingly, Med $23^{-1-}$ T cells were larger in size compared with WT T cells (Fig. 2a). In addition, $\mathrm{T}$ cells from $\mathrm{Med} 23^{-1-}$ mice showed enhanced expression of activation markers, including CD69, $\mathrm{CD} 25$ and CD44, compared with $\mathrm{T}$ cells from WT mice (Fig. 2b-d). These results indicate that $M e d 23^{-1-} \mathrm{T}$ cells have an activated phenotype in the periphery. Med $23^{-1-}$ mice also had a higher number of $\mathrm{CD} 62 \mathrm{~L}^{\text {low }} \mathrm{CD} 44^{\text {high }} \mathrm{CD} 4^{+} \mathrm{T}$ cells with an activated phenotype and a lower number of CD62 high $\mathrm{CD} 44^{\text {low }}$ naive T cells (Fig. 2e,f). The CD44high cell compartment contains both recently activated and memory-phenotype $\mathrm{T}$ cells $^{31}$. Our analysis further revealed that the CD44high compartment of Med23 $1-$ T cells mainly consisted of activated $\mathrm{T}$ cells, but not memory-phenotype $\mathrm{T}$ cells (Supplementary Fig. 2a,b). The hyperactivation of T cells in $M e d 23^{-I-}$ mice may have resulted from reduced Tregs; however, our results showed that $\operatorname{Med} 23^{-1-}$ mice contained the same Treg cell proportion as WT mice (Supplementary Fig. 2c,d). Moreover, adoptive transfer experiments indicated a cell-intrinsic role for Med23 in controlling T-cell activation (Supplementary Fig. 3a,b).

Med23 deficiency causes autoimmune symptoms. In addition to the lymph nodes and spleen, other organs and tissues including the liver, lung, kidney and blood showed a higher proportion of CD69-, CD25- and CD44-expressing T cells in the absence of Med23 (Fig. 3a and Supplementary Fig. 4). This result suggests that Med23 deficiency may lead to the development of autoimmune symptoms ${ }^{32}$. To further investigate whether $\operatorname{Med} 23$ deficiency caused spontaneous autoimmune disease, autoimmune 
a

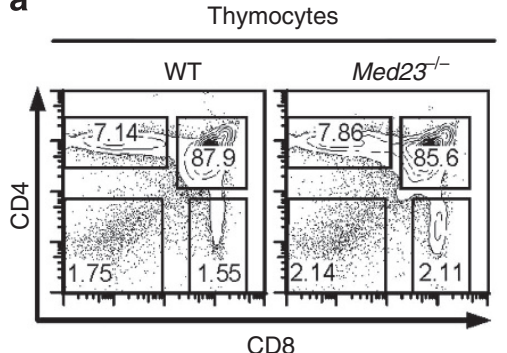

C

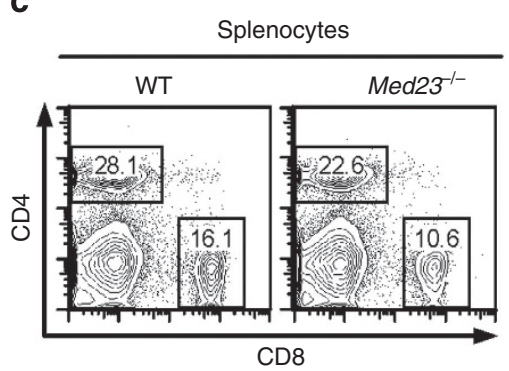

e

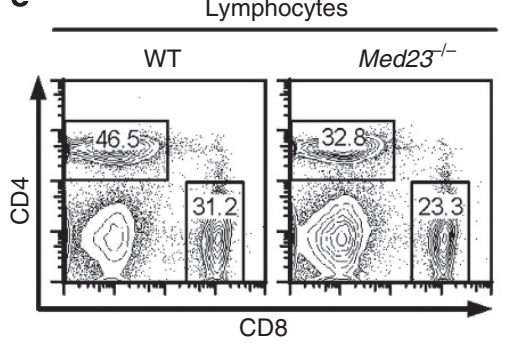

b
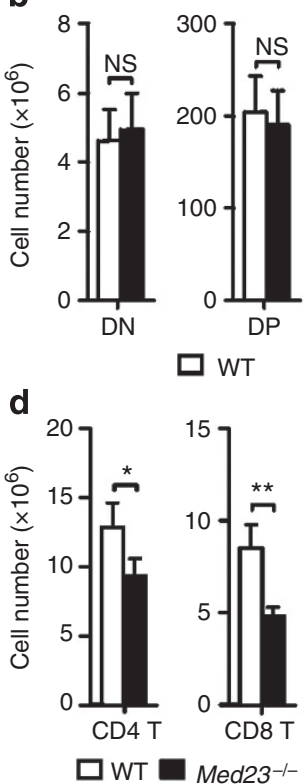

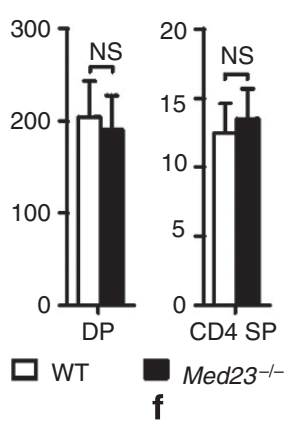

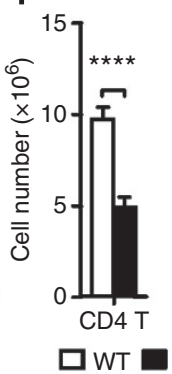

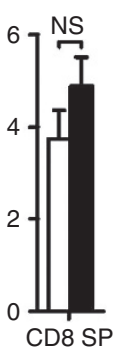

g
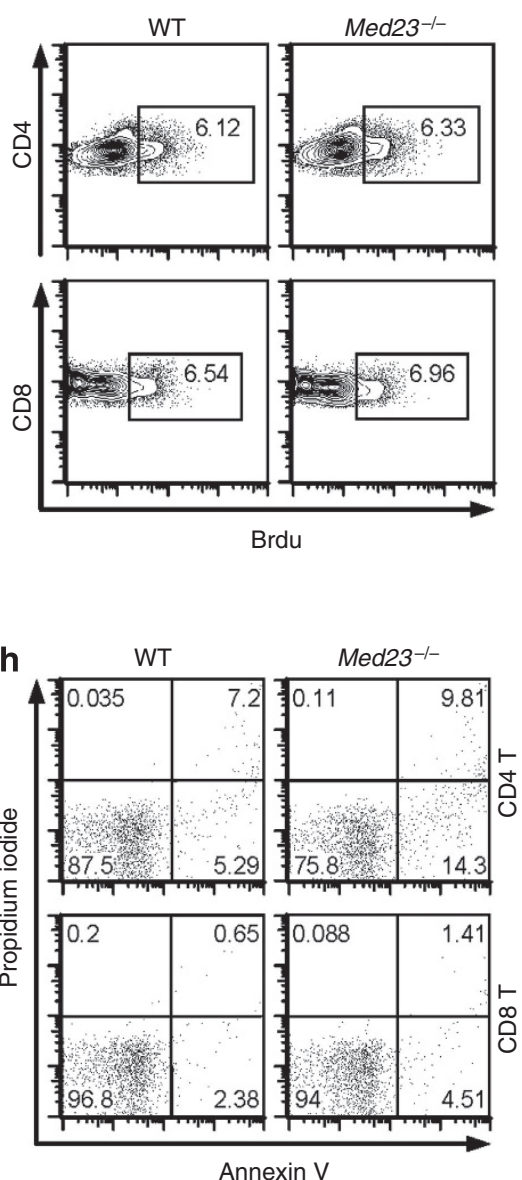

Figure 1 | Med23 deficiency leads to a reduction in peripheral T cells. (a) Total thymocytes from WT and Med23-/ ${ }^{-}$mice were analysed for CD4 and CD8 expression by flow cytometry. (b) Total number of CD4 ${ }^{-} \mathrm{CD} 8^{-}$double-negative (DN), $C D 4^{+} \mathrm{CD}^{+}$double-positive (DP), $\mathrm{CD} 4^{+}$single-positive (CD4 SP) and $\mathrm{CD}^{+}$single-positive (CD8 SP) thymocytes ( $n=13$; NS, no significance). (c) Flow cytometry analysis of CD4 and CD8 expression on splenocytes from WT and Med23-/- mice. (d) Total number of $\mathrm{CD} 4^{+}$and $\mathrm{CD} 8^{+}$splenic T cells $\left(n=13 ;{ }^{\star} P<0.05\right.$ and ${ }^{\star \star} P<0.01$ by Student's $t$-test). (e) Flow cytometry analysis of CD4 and CD8 expression on lymphocytes from WT and Med23-/ $3^{-}$mice. (f) Total number of CD4 ${ }^{+}$and CD8 ${ }^{+}$ lymphocytic T cells $\left(n=11 ;{ }^{\star} P<0.05\right.$ and ${ }^{\star \star \star \star} P<0.0001$ by Student's $t$-test). (g) 5-Bromo-2'-deoxyuridine (BrdU) incorporation of T cells from WT and Med23 $3^{-/}$mice after injection of BrdU. (h) Survival of T cells was assessed by flow cytometry analysis of Annexin $\mathrm{V}$ and propidium iodide (PI) staining. (i) Percentage statistics for Annexin V and PI staining of T cells from WT and Med23 ${ }^{-/}$- mice $\left(n=11 ;{ }^{\star} P<0.05,{ }^{\star \star} P<0.01\right.$ and ${ }^{\star \star \star} P<0.001$ by Student's t-test; NS, no significance). Error bars indicate s.e.m. All results are representative of or combined from at least three independent experiments.

traits were analysed in Med23-/- mice aged 15-18 months. Although no autoimmune disease was observed, autoimmune symptoms were clearly detected. For example, there was an apparent infiltration of mononuclear cells detected near the vessels of the lungs and livers in aged Med23 $3^{-/}$mice (Fig. 3b), with more serious mononuclear cell infiltration observed in the lungs (no infiltration was detected in the kidneys). Together, three out of four aged Med23 $1-$ mice developed severe mononuclear cell infiltration. In contrast, no apparent infiltration was detected in WT mice. Moreover, aged Med23 ${ }^{-I}$ mice exhibited not only higher titres of antidsDNA antibodies (Fig. 3c) but also higher levels of IFN $\gamma$ in their sera compared with WT mice (Fig. 3d). Cumulatively, Med23 deficiency led to an autoimmune syndrome in aged mice, which suggests that Med23 is involved in maintaining T cell selftolerance and the prevention of autoimmunity.

Med23 ${ }^{-I-} \mathrm{T}$ cells are more sensitive to TCR stimulation. The aforementioned results indicated that Med23 deficiency led to a T-cell hyperactivation phenotype, although we cannot exclude the potential confounding effect of differences in proliferation and effector function. We then examined whether Med23-deficient $\mathrm{T}$ cells were more sensitive than WT $\mathrm{T}$ cells on short-term TCR stimulation. Indeed, Med $23^{-/}-\mathrm{T}$ cells showed increased expression of both CD25 and CD69 on TCR stimulation compared with WT T cells (Fig. 4a,b). In addition, $M e d 23^{-1-} \mathrm{CD} 4^{+}$ and $\mathrm{CD}^{+} \mathrm{T}$ cells proliferated more rapidly than $\mathrm{WT} \mathrm{T}$ cells (Fig. 4c) and exhibited enhanced production of IFN $\gamma$ (Fig. 4d). Moreover, T cells from Med23 ${ }^{-T}-$ mice consistently showed enhanced activation on TCR stimulation with different antibody doses and at different timepoints (Fig. 4e), which indicated that Med23 ${ }^{-I}-\mathrm{T}$ cells might have a lower activation threshold than WT T cells. This enhanced activation was not found when T cells were treated with the cytokine IL-7, which is reported to play a role in T-cell quiescence ${ }^{33}$. IL-7 receptor (IL-7R) expression and the proliferation of $\mathrm{T}$ cells in response to IL-7 were not changed in the absence of Med23 (Supplementary Fig. 5a,b). Together, our data indicated that the loss of Med23 led to increased T-cell sensitivity to TCR stimulation, which might be due to a lower activation threshold in Med23-I- T cells. 
a

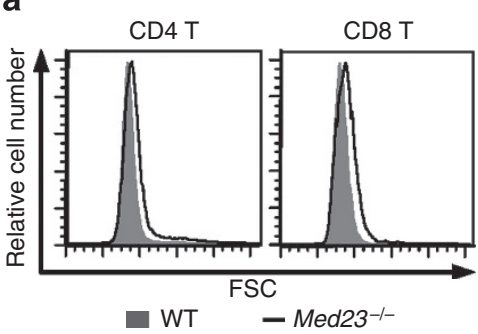

b

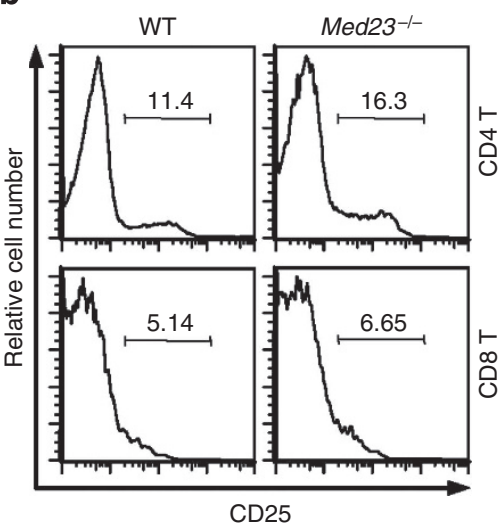

C

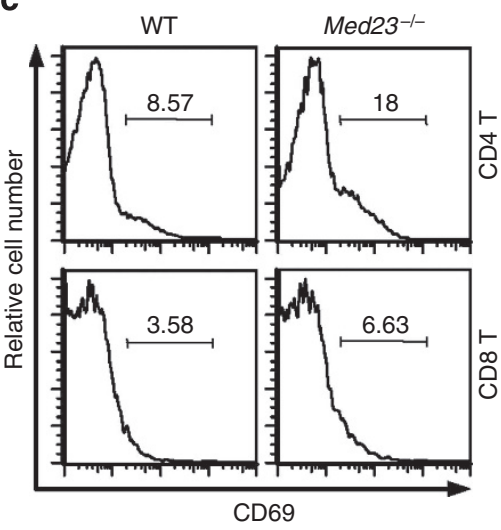

d

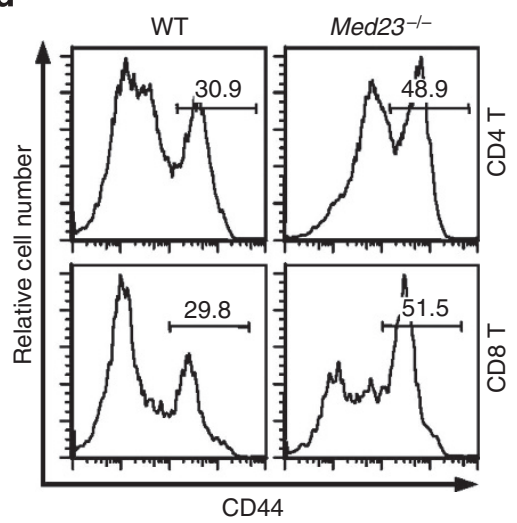

e

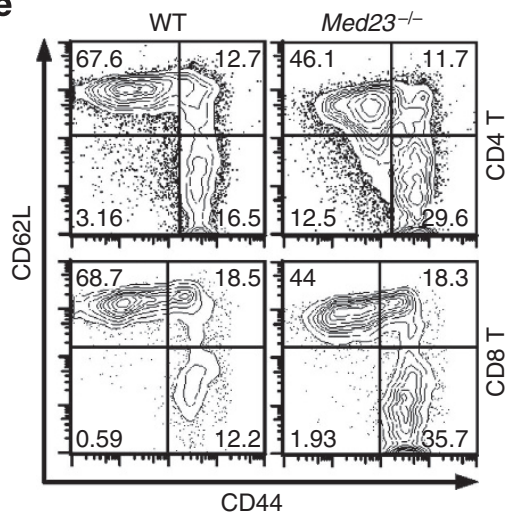

f

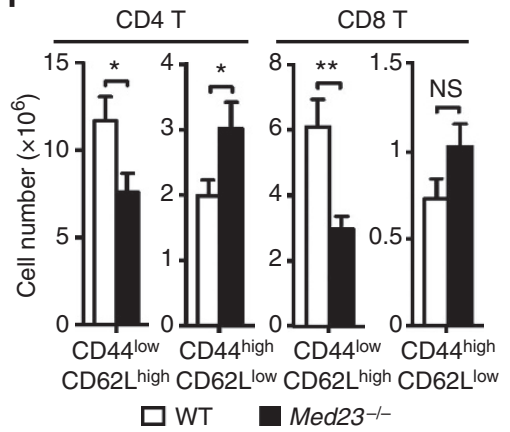

Figure 2 | Med23-deficient T cells exhibit a hyperactivated phenotype. (a) Size of freshly isolated WT and Med23-/ - T cells. FSC, forward scatter. $\mathrm{CD}^{+}$or $\mathrm{CD}^{+}$T cells from Med23-/- and WT mice were stained for the surface markers CD25 (b), CD69 (c) and CD44 (d) and analysed by flow cytometry. (e) Expression of CD62L and CD44 on splenic T cells. (f) Total number of CD44 ${ }^{\text {low }}$ CD62 ${ }^{\text {high }}$ and CD44 ${ }^{\text {high }}$ CD62L ${ }^{\text {low }}$ splenic T cells $\left(n=13 ;{ }^{\star} P<0.05\right.$ and ${ }^{\star \star} P<0.01$ by Student's $t$-test; NS, no significance). Error bars indicate s.e.m. All results are representative of or combined from at least three independent experiments.

Med23 promotes the transcription of negative regulators. We next examined TCR signal transduction and the detailed mechanisms involved in the regulation of $\mathrm{T}$-cell activation by Med23. Similar phosphorylation of key molecules associated with TCR signal transduction was detected in Med23-I- and WT T cells on stimulation (Fig. 4f), suggesting that Med23 may regulate T-cell activation without affecting TCR signalling.

Due to the indispensable roles of Med23 and the mediator complex in gene transcription, we compared the gene expression profiles between $\mathrm{Med} 23^{-I-}$ and WT T cells before and after TCR stimulation. Gene ontology analysis showed that the expression of genes encoding negative regulators of $\mathrm{T}$-cell activation was downregulated in stimulated $\mathrm{Med} 23^{-1-} \mathrm{CD} 4^{+}$ $\mathrm{T}$ cells (data available on GEO: GSE60779). For example, both Krüppel-like Factor 2 (Klf2) and Forkhead box protein P1
(Foxp1), which encode transcription factors known to regulate naïve T-cell quiescence ${ }^{33-35}$, were downregulated after TCR stimulation in Med23 $-I-$ T cells. Furthermore, the expression of many genes encoding molecules associated with T-cell activation were upregulated, including cytokines (IFN $\gamma$, IL-4, IL-2 and so on), cell surface molecules (CD44, CD40, CD70, CD86 and so on), transcription factors and cell cycle regulators (Supplementary Fig. 6). In fresh T-cell samples, the early growth response 1 (Egrl), encoding a member of the EGR family, was downregulated by 2.2 -fold. In addition, the key negative regulator of T-cell activation Egr2 (ref. 36) was downregulated by 1.7 -fold. We also validated the expression of these genes using real-time PCR in sorted naïve $\mathrm{CD} 4{ }^{+} \mathrm{T}$ cells after TCR stimulation and in freshly sorted naïve CD4 ${ }^{+} \mathrm{T}$ cells, and this analysis confirmed the downregulation of Egr1, Egr2 and 

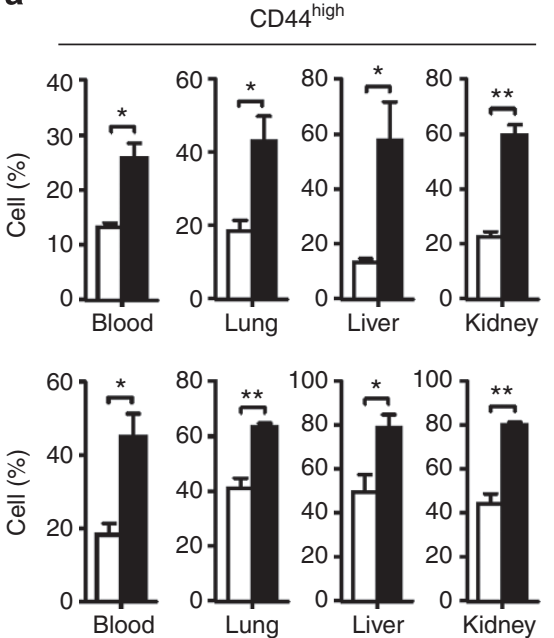

CD25 high
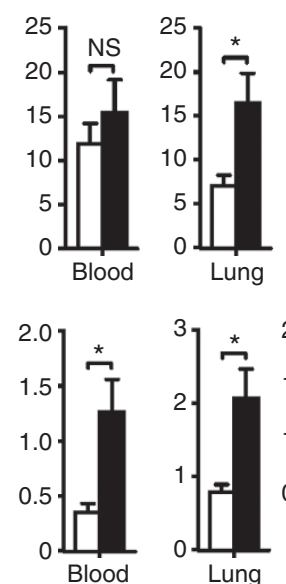
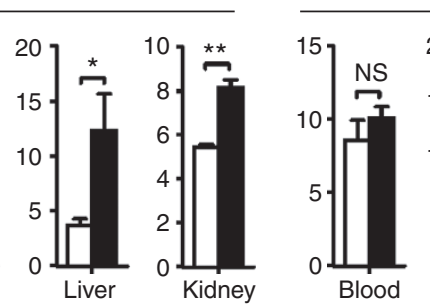

CD69high
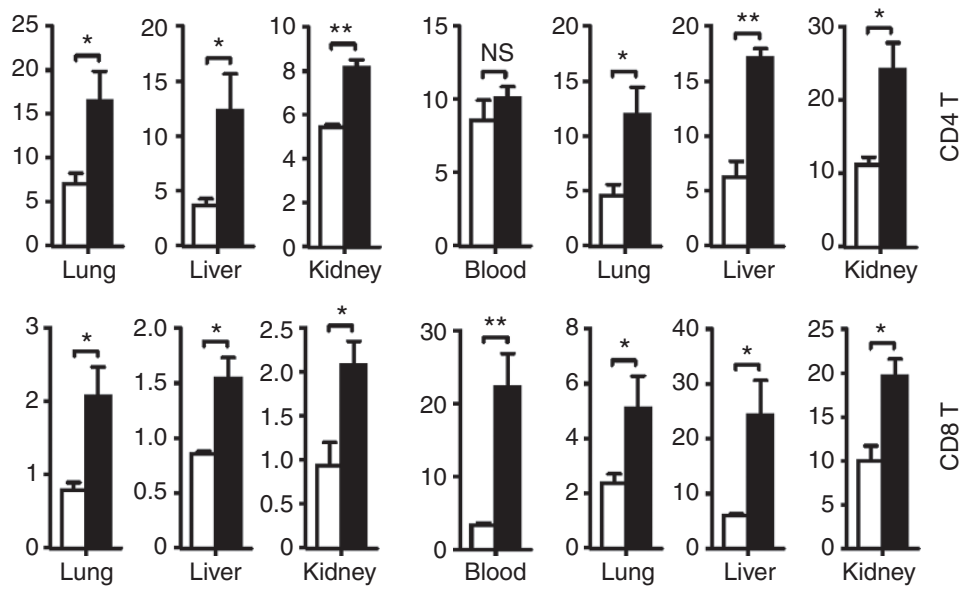

$\square$ WT

$\mathrm{Med}_{23^{-/}}$

d

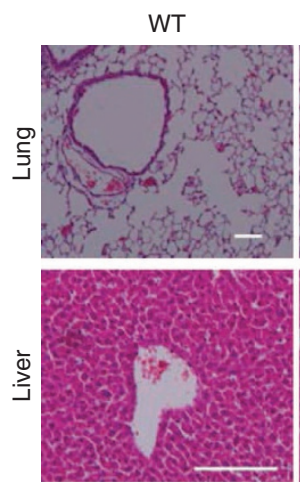

$\times 100$
$\mathrm{Med}_{23^{-/}}$
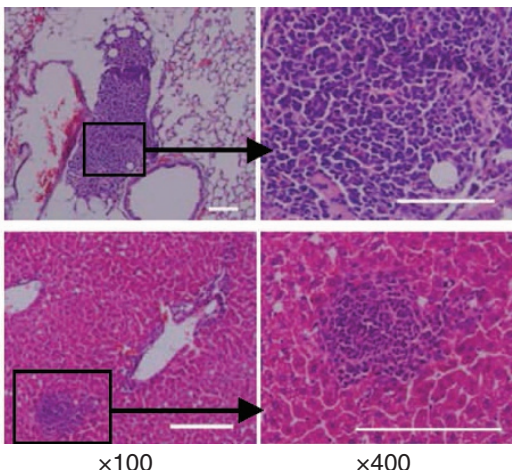

C

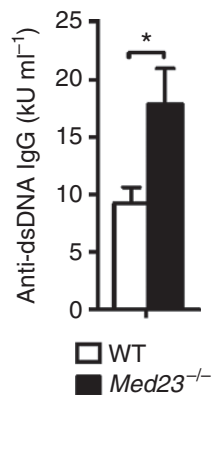

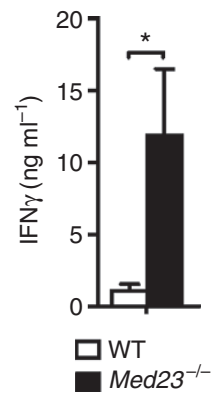

Figure 3 | Loss of Med23 results in autoimmune symptoms. (a) Percentage statistics for CD44, CD25 and CD69 expression in isolated T cells from the blood or indicated organs (kidney, $n=3$; blood and liver, $n=4$; lung, $n=7$; ${ }^{\star} P<0.05$ and ${ }^{\star \star} P<0.01$ by Student's $t$-test; NS, no significance). (b) Mononuclear cell infiltration in the lung and liver of Med23-/- and WT mice (15- to 18-month-old) was visualized by haematoxylin and eosin staining (magnification, $\times 100$ and $\times 400$; scale bars, $100 \mu \mathrm{M}$ ). The anti-dsDNA IgG (c) or IFN $\gamma$ concentration (d) in the serum of aged mice (15- to 18-month-old) was assessed by enzyme-linked immunosorbent assay (anti-dsDNA, $n=4 ;$ IFN $\gamma, n=3$; ${ }^{\star} P<0.05$ by Student's $t$-test). Error bars indicate s.e.m. All results are representative of or combined from at least three independent experiments.

Klf2 in unstimulated $\mathrm{CD} 4^{+} \mathrm{T}$ cells but revealed no obvious change in Foxp1. However, in stimulated CD4 ${ }^{+} \mathrm{T}$ cells, all four genes were significantly downregulated (Fig. 5a).

To investigate the mechanism by which Med23 deficiency inhibits gene transcription, we performed a chromatin immunoprecipitation (ChIP) assay using an antibody against Pol II. The results indicated that the depletion of Med23 reduced the recruitment of Pol II to the promoter region of Egr1, Egr2 and Klf2 in both freshly sorted and TCR-stimulated naïve CD4 ${ }^{+}$ $\mathrm{T}$ cells (Fig. 5b), which correlated with their low-level transcription (Fig. 5a). Moreover, Med23 deficiency did not influence the recruitment of Pol II to the promoter region of Foxp1 (Fig. 5b). Taken together, these data suggested that Med23 was required for active transcription of Egr1, Egr2 and Klf2 in both stimulated and naïve $\mathrm{CD} 4{ }^{+} \mathrm{T}$ cells.

Because deletion of either Egr2 or Klf2 leads to an activated T-cell phenotype ${ }^{34,37}$, we sought to address whether the ectopic expression of either Egr2 or Klf2 could attenuate the hyperactivation of $\mathrm{Med} 23^{-/-} \mathrm{T}$ cells. Consistent with the above observation, Med23-I- T cells showed significantly higher expression of CD69 compared with WT T cells on TCR stimulation. However, this enhanced expression was reduced to WT levels in T cells transfected with either Egr2 or Klf2 (Fig. 5c).
Notably, Med23 expression was slightly increased in $\mathrm{T}$ cells on TCR stimulation (Supplementary Fig. 7), which might sequentially promote the transcription of negative regulators of T-cell activation (Fig. 5a). Taken together, these results indicated that the hyperactivation of Med23-deficient $\mathrm{T}$ cells could be caused by the downregulation of negative regulators of $\mathrm{T}$-cell activation in the absence of Med23.

Med23 deficiency enhances antitumour T-cell function. Considering that the T-cell activation threshold is low in the absence of Med23, we next examined whether it was able to promote T-cell suppression of spontaneous tumour growth. To address this issue, we used mammary epithelium-specific transgenic mice that express the polyomavirus middle $\mathrm{T}$ antigen (PyMT) under transcriptional control of the mouse mammary tumour virus long terminal repeat ${ }^{38}$. Female transgenic mice develop palpable mammary tumours at 5-40 weeks of age, and these mice were crossed with $\mathrm{Med} 23^{-1-}$ mice to generate PyMT Med23-I- mice, with PyMT transgenic mice (PyMT WT) serving as littermate controls. We observed that the time of tumour onset in PyMT Med23 $-1-$ mice was delayed compared with that in PyMT WT mice (Fig. 6a). Moreover, histological 
a

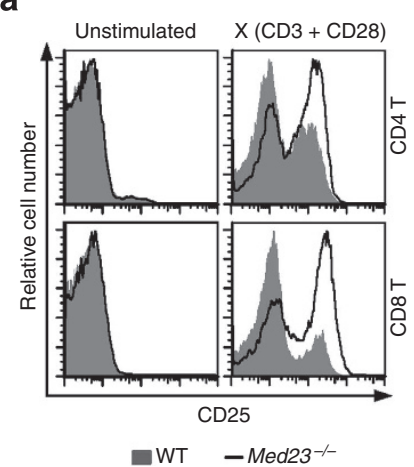

d

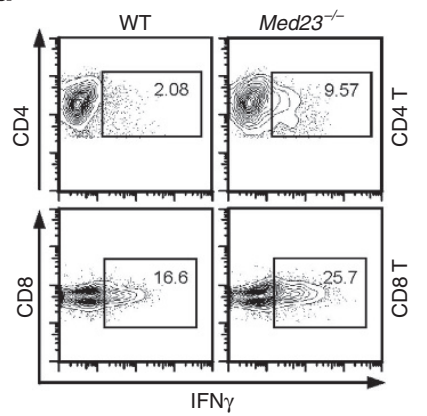

b

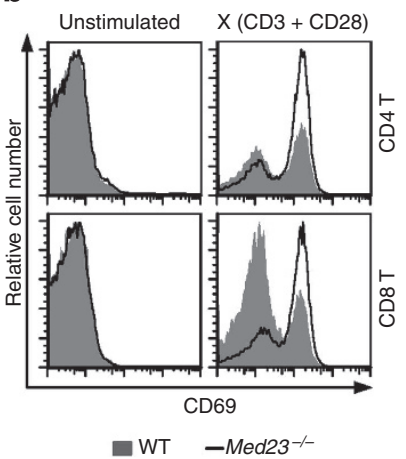

C

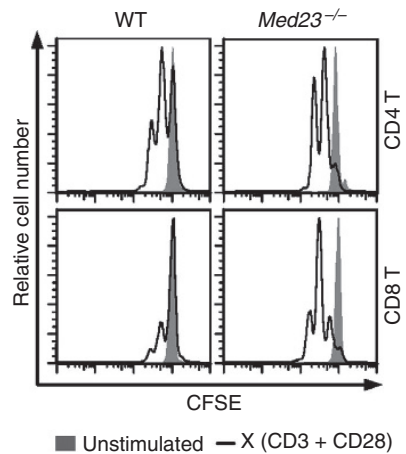

$\mathbf{f}$
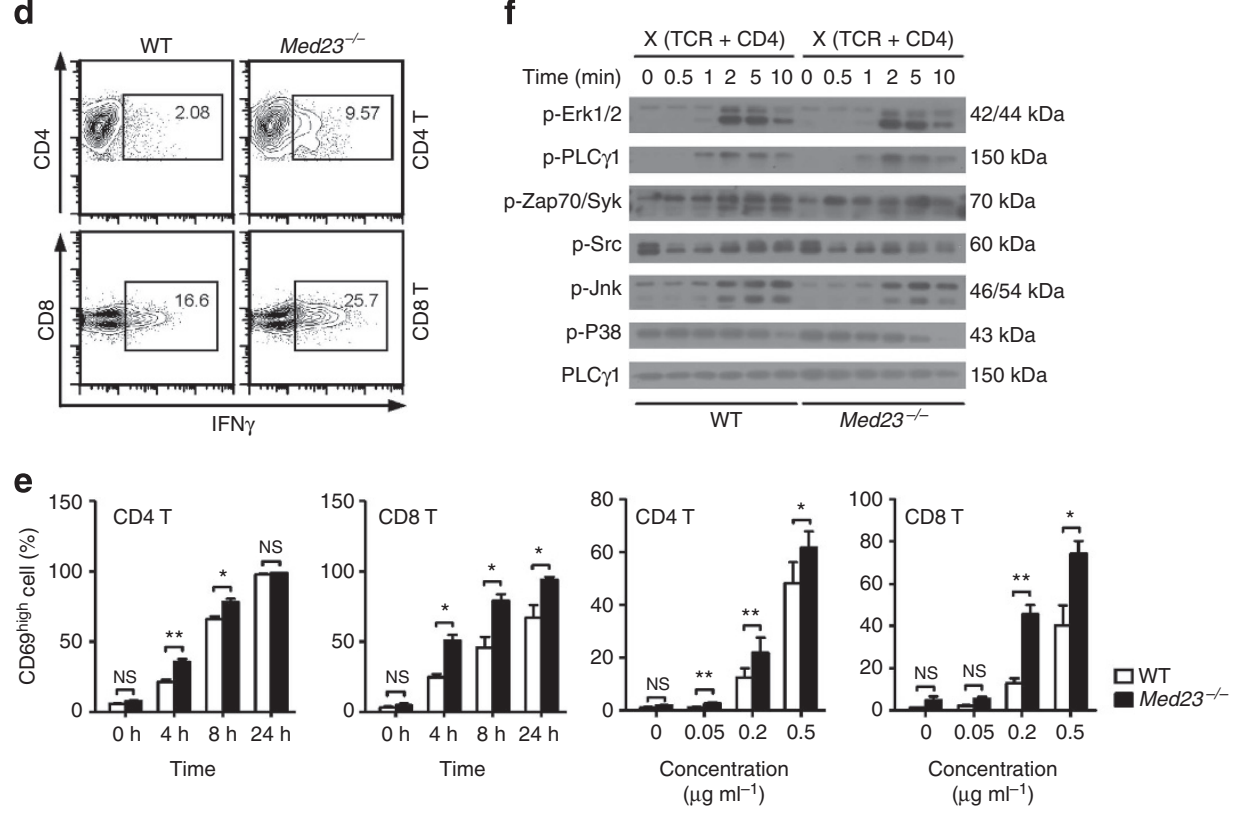

Figure 4 | Med23 ${ }^{-/}$T cells are hyper-responsive to TCR stimulation. Flow cytometry analysis of CD25 (a) and CD69 (b) expression on naïve T cells. Purified naïve T cells were unstimulated or stimulated with anti-CD3 $\left(1 \mu \mathrm{g} \mathrm{ml}^{-1}\right)$ and anti-CD28 $\left(1 \mu \mathrm{g} \mathrm{ml}{ }^{-1}\right)$ antibodies for $16 \mathrm{~h}$. (c) T-cell proliferation was measured by carboxyfluorescein succinimidyl ester (CFSE) dilution. Purified naïve T cells were stained with CFSE and stimulated using anti-CD3 $\left(1 \mu \mathrm{g} \mathrm{ml}^{-1}\right)$ and anti-CD28 $\left(1 \mu \mathrm{g} \mathrm{ml}^{-1}\right)$ antibodies for $48 \mathrm{~h}$ before fluorescence-activated cell sorting analysis. (d) IFN $\gamma$ production from naïve T cells was analysed by flow cytometry. Purified naïve T cells were stimulated with anti-CD3 $\left(1 \mu \mathrm{g} \mathrm{ml}^{-1}\right)$ and anti-CD28 $\left(1 \mu \mathrm{g} \mathrm{ml} \mathrm{I}^{-1}\right)$ antibodies and restimulated with PMA and ionomycin for $4 \mathrm{~h}$ before intracellular staining. (e) Flow cytometry-sorted naive T cells were stimulated with anti-CD3 and antiCD28 antibodies at various antibody concentrations and stimulation timepoints, and the expression of the surface marker CD69 was analysed by flow cytometry $\left(n=3 ;{ }^{\star} P<0.05\right.$ and ${ }^{\star \star} P<0.01$ by Student's $t$-test; NS, no significance). (f) Naive CD4 ${ }^{+}$T cells from WT and Med $23^{-/}-$mice were labelled with biotinylated anti-TCR $\left(10 \mathrm{mg} \mathrm{ml}^{-1}\right)$ and anti-CD4 $\left(10 \mathrm{mg} \mathrm{ml}^{-1}\right)$ antibodies and then cross-linked with streptavidin for the indicated times or left untreated $(0 \mathrm{~min})$. Total lysates from these cells were subjected to SDS-polyacrylamide gel electrophoresis and analysed with antibodies against the tyrosine-phosphorylated form of Erk1/2, Plc 1 1, Src, Zap70/Syk, Jnk or P38. The expression of total Plc $\gamma 1$ served as a loading control. Error bars indicate s.e.m. All results are representative of or combined from three independent experiments. All naïve T cells were sorted by flow cytometry based on high expression of CD62L and low expression of CD44.

analysis of the tumours showed that tumour development was significantly repressed in PyMT Med23-/- mice, whereas invasive tumour growth was observed in PyMT WT mice (Fig. 6b). Our results further showed that mammary tumour growth was reduced in Med23-deficient mice (Fig. 6c). In addition, tumour-infiltrating T cells in PyMT Med23-I- mice showed higher expression of CD44 than counterparts from PyMT WT mice (Fig. 6d). Furthermore, tumour-infiltrating $\mathrm{T}$ cells in PyMT Med23- ${ }^{-}$mice produced more antitumour cytokines than counterparts from PyMT WT mice, including IL-2, IFN $\gamma$ and tumour necrosis factor $\alpha$ (TNF $\alpha$ ) (Fig. 6e-g). In addition, the number of granzyme B-expressing $\mathrm{CD} 8{ }^{+} \mathrm{T}$ cells decreased, whereas the number of perforin-expressing $\mathrm{CD}^{+} \mathrm{T}$ cells increased, in PyMT Med23-l- mice (Fig. 6h,i). Collectively, these data indicated that antitumour T-cell function was enhanced in the absence of Med23 and that Med23-I- T cells were able to eliminate transformed cells at an early stage during immunosurveillance.

\section{Discussion}

Although it has been reported that the mediator subunit Med23 plays significant roles in diverse biological processes ${ }^{26-29}$, the role of Med23 in immune responses remains unknown. In this study, we identified Med23 as an important regulator of T-cell activation. Specifically, we found that specific deletion of Med23 in $\mathrm{T}$ cells led to impaired $\mathrm{T}$-cell homeostasis, including reduced peripheral T-cell numbers, increased T-cell size and T-cell 
a

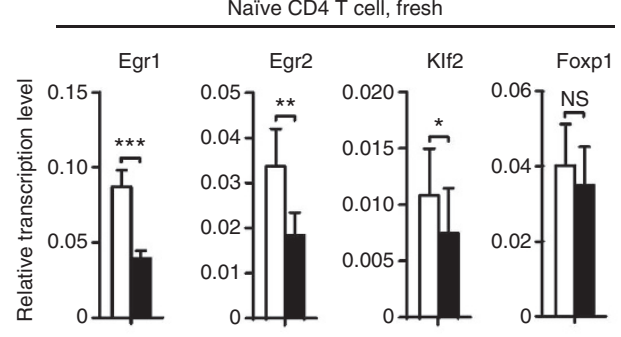

Naïve CD4 T cell, X (CD3 + CD28)

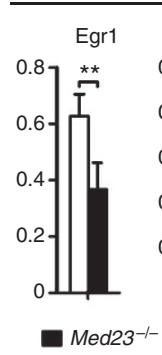

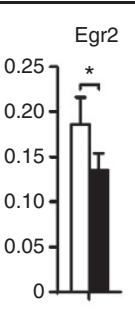

C

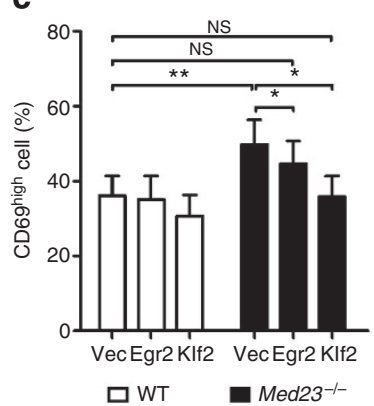

口WT b

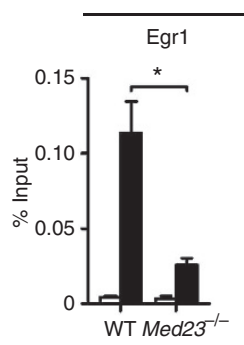

Naïve CD4 T cell, fresh

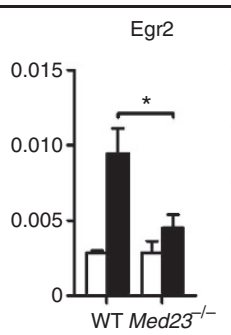

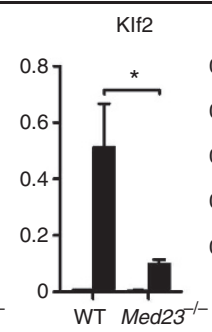

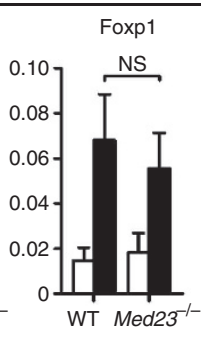

$\square \lg \mathrm{C}$ tr

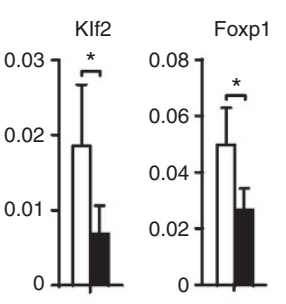

Naïve CD4 T cell, $X(C D 3+$ CD28)

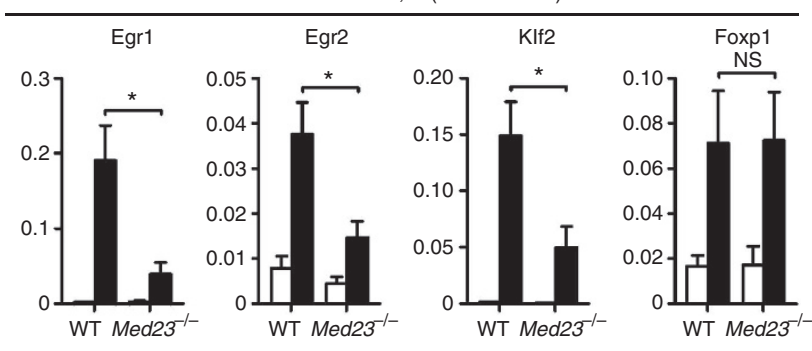

Figure 5 | Med23 promotes the transcription of negative regulators of T-cell activation. (a) Real-time reverse transcriptase-PCR assay for Egr1, Egr2, KIf2

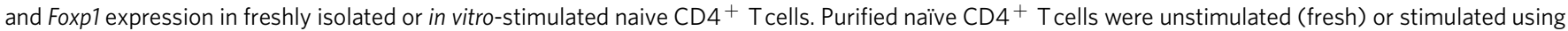
plate-bound anti-CD3 $\left(1 \mu \mathrm{g} \mathrm{ml}{ }^{-1}\right)$ and anti-CD28 $\left(1 \mu \mathrm{g} \mathrm{ml}{ }^{-1}\right)$ antibodies (Egr1 and Egr2, $n=7 ; K I f 2$ and Foxp1, $n=6 ;{ }^{\star} P<0.05,{ }^{\star \star} P<0.01$ and ${ }^{\star \star \star} P<0.001$ by Student's t-test; NS, no significance). The relative transcription levels of target genes were normalized to Gapdh. Naïve T cells were sorted by flow

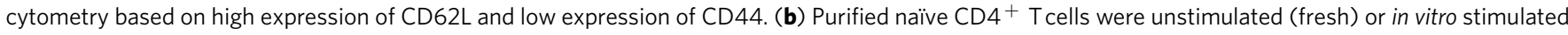
and lysed for ChIP assays (Egr1 and Egr2, $n=3$; KIf2 and Foxp1, $n=4 ;{ }^{\star} P<0.05$ by Student's $t$-test; NS, no significance). (c) Ratio statistics for CD69 expression, as examined by flow cytometry, in stimulated naïve CD4 ${ }^{+}$T cells transfected with lentiviral constructs. Purified naïve CD4 ${ }^{+}$T cells transfected with vector, Egr2 or Klf2 lentiviral constructs were in vitro stimulated using plate-bound anti-CD3 (1 $\left.\mu \mathrm{g} \mathrm{ml}{ }^{-1}\right)$ and anti-CD28 ( $\left.1 \mu \mathrm{g} \mathrm{ml}-1\right)$ antibodies and evaluated by fluorescence-activated cell sorting analysis (Vector and Egr2, $n=8$; KIf2, $n=7$; ${ }^{\star} P<0.05$ and ${ }^{\star \star} P<0.01$ by Student's $t$-test). Error bars indicate s.e.m. All results are combined from at least three independent experiments.

hyperactivation. Furthermore, aged Med23-deficient mice exhibited autoimmune syndrome features such as mononuclear cell infiltration in organs and higher titres of anti-dsDNA antibodies in sera. On the other side, Med23 deficiency enhanced antitumour T-cell function and repressed tumour growth. Given that Med23 is one of the tail modules of the mediator complex that controls a distinct gene expression pattern, our data suggest that Med23 may function as a key regulator of transcription that contributes to controlling $\mathrm{T}$-cell activation to maintain $\mathrm{T}$-cell homeostasis and self-tolerance.

Med23 is known to mediate serum mitogen-induced IEGs expression, especially that of the EGR family genes ${ }^{25,26}$. Our gene expression analysis by microarray before or after TCR stimulation revealed that Med23-deficient $\mathrm{T}$ cells had reduced expression of Egr1 and Egr2, and these results were confirmed by real-time PCR analysis. Importantly, Egr2 has been identified as a key negative regulator of $\mathrm{T}$-cell activation by influencing Cbl-b expression $^{36}$, and Cbl-b is known to set the T-cell activation threshold for autoimmunity ${ }^{39}$. Conversely, Egr1 plays an opposite role in T-cell activation compared with Egr2 (ref. 40). Correspondingly, T-cell hyperactivation could be partially dampened by the overexpression of Egr2 in our study. In addition to the IEGs, Med23-deficient T cells also failed to sustain the expression of Klf2, which has been reported to play an important role in regulating $\mathrm{T}$-cell activation ${ }^{34,35}$. Furthermore, the ectopic expression of Klf2 also partially dampened Med23deficient T-cell hyperactivation. Consistent with the increased Med23 expression in T cells on TCR stimulation, our data suggest that Med23 may work as an intrinsic hub for transcriptional regulation of T-cell activation regulators. We also identified Klf2 as a novel target that is regulated at the transcriptional level by Med23 in T cells.

Precise control of $\mathrm{T}$-cell activation ensures that $\mathrm{T}$ cells can discriminate between foreign and self-antigens to promote effective immune response without fostering autoimmunity $3,37,39$. Losing control of T-cell activation may result in autoimmunity due to inappropriate activation in response to self-antigens $3,37,39$. In our study, hyperactivation and higher sensitivity to TCR stimulation were detected in Med23-deficient T cells. In addition, mononuclear cell infiltration in organs and a higher titre of antidsDNA antibodies in the sera were also found in Med23-deficient mice. These results imply that Med23 deficiency could cause an autoimmune disease-like phenotype due to a decreased T-cell activation threshold, although we did not definitely demonstrate that Med23 sets the activation threshold of individual $\mathrm{T}$ cells rather than regulating the subsequent proliferative response. On the other side, we also found that Med23 deficiency enhanced antitumour T-cell function and repressed tumour growth. It is possible that the decreased activation threshold of Med23deficienct $\mathrm{T}$ cells may enhance $\mathrm{T}$-cell responses against particular antigens, such as self-antigens, and may be useful in the treatment of diseases such as cancer.

The T-cell activation threshold is a single-cell parameter and represents the minimum TCR signal required to elicit a response that triggers T-cell activation $3,9,41$ Recent evidence suggests that the T-cell activation threshold can be modified by the following factors: (1) changes in TCR signal strength ${ }^{39,42}$; (2) regulation of costimulatory signalling ${ }^{9,43}$; (3) interactions between $\mathrm{T}$ cells and 
a

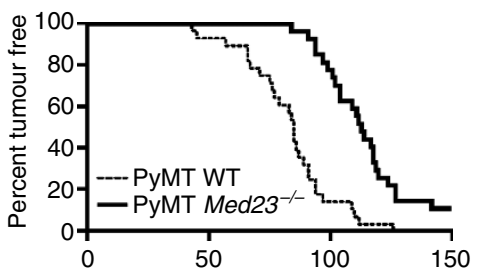

d

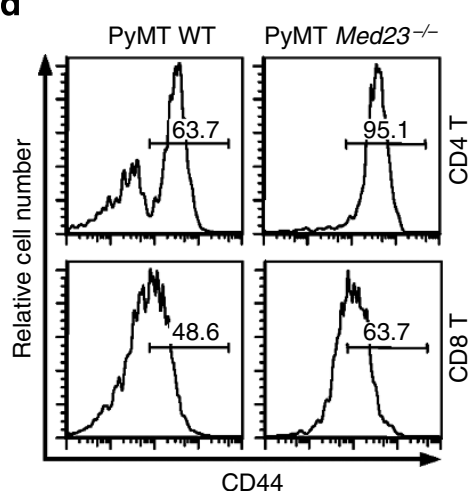

g

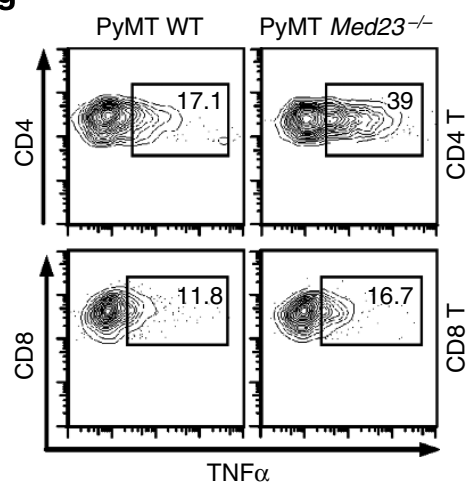

b

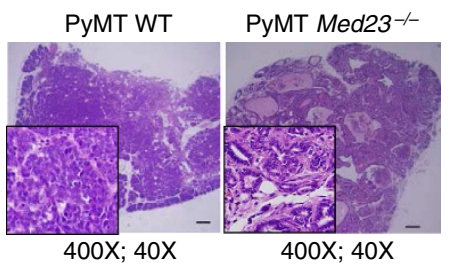

e

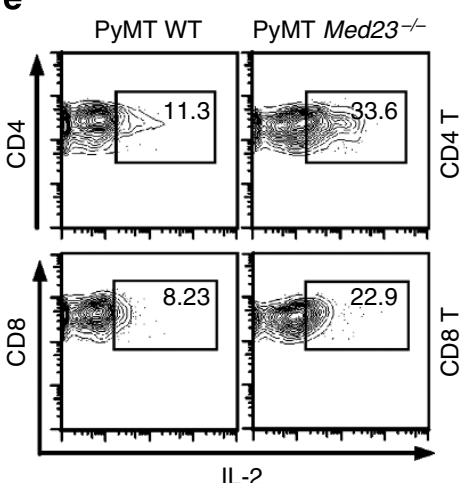

h

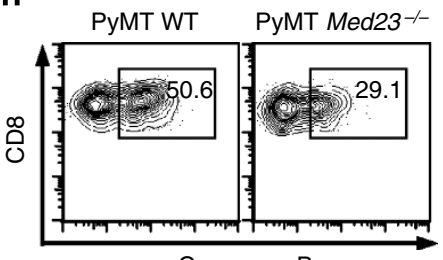

Granzyme B

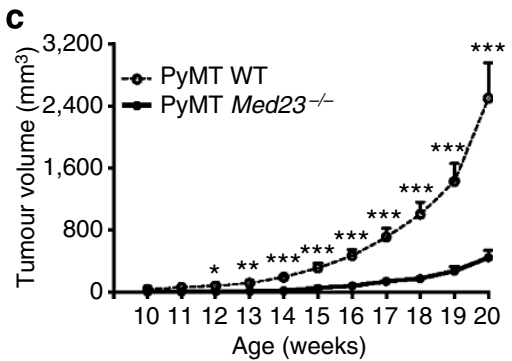

f
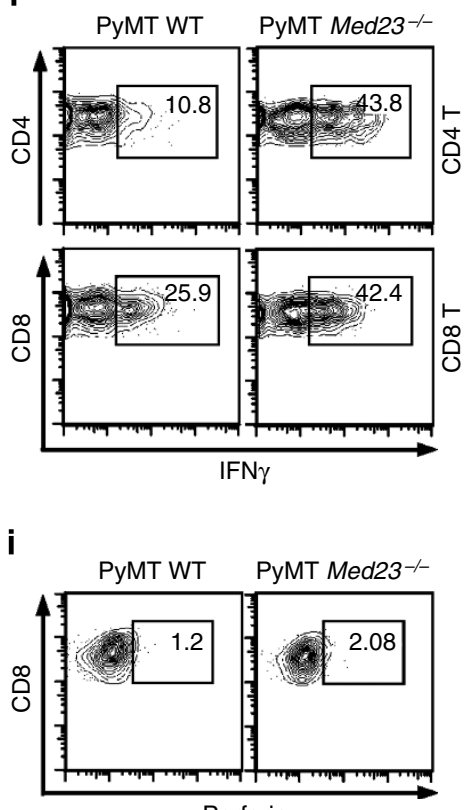

Figure 6 | Med23 deficiency enhances the antitumour function of T cells. (a) Tumour onset was monitored for PyMT WT and PyMT Med23- ${ }^{-}-$mice (PyMT WT, $n=28$; PyMT Med23-/,$- n=27 ; P<0.0001$ by log-rank test). (b) Haematoxylin and eosin-stained mammary tumour sections of PyMT WT and PyMT Med23 ${ }^{-/}$mice (magnification, $\times 40$ and $\times 400$; scale bars, $200 \mu \mathrm{m}$ ) (c) Tumour growth in PyMT WT and PyMT Med23-/ - mice. Mammary tumour volumes were measured with calipers starting from 6 weeks after birth and continuing until 20 weeks of age (PyMT WT, $n=20$; PyMT Med23 ${ }^{-/}-, n=16 ;{ }^{\star} P<0.05,{ }^{\star \star} P<0.01$ and ${ }^{\star \star \star} P<0.001$ by Student's $t$-test). (d) Flow cytometry analysis of CD44 expression in tumour-infiltrating T cells. The production of IL-2 (e), IFN $\gamma(\mathbf{f})$ and TNF $\alpha(\mathbf{g})$ from tumour-infiltrating T cells was analysed by flow cytometry. Granzyme B (h) and perforin (i) expression in tumour-infiltrating $\mathrm{CD}^{+}{ }^{+} \mathrm{T}$ cells was assessed. Error bars indicate s.e.m. All results are representative of or combined from at least three independent experiments.

$\mathrm{APCs}^{44}$; and (4) regulation of chromosome propagation ${ }^{45}$. Most mechanisms involved in setting the activation threshold are dependent on signalling transduction; however, our work potentially proposes a novel regulation mechanism for $\mathrm{T}$-cell activation threshold that functions at the transcriptional level.

The tunable T-cell activation threshold model ${ }^{3,41}$ proposes that $\mathrm{T}$-cell responsiveness is dynamically adjusted during recurrent encounters of the cell with self-antigens. Tuning amounts to maintaining a level of induced or recruited negative regulators sufficient to anticipate and block activation of the cell by such self-antigens despite fluctuations while maintaining the capacity to be activated by more potent antigenic stimulation. Many efforts have been invested in revealing the identity and organization of the negative regulators ${ }^{4-6,16,35,36}$. Our study represents such an effort, linking responsiveness to negative regulation of activation. Whether regulation is of the transition between complete quiescence to full activation, and in that case whether it is dynamically geared to ongoing 'subthreshold' interactions or whether only the T-cell response post activation is subject to regulation by the cellular elements studied here, remains beyond the scope of this study, although our analysis suggests that the latter possibility cannot fully account for all the observations.

\section{Methods}

Mice. $M e d 23^{\mathrm{f} / \mathrm{fl}}$ mice ${ }^{28}$ and $C d 4$ Cre transgenic mice have been described previously ${ }^{28,46}$. PyMT transgenic mice, recombination-activating gene 1-deficient mice, and CD $45.1^{+}$mice were obtained from The Jackson Laboratory. All mice were maintained in a specific pathogen-free facility in the Shanghai Laboratory Animal Center (Chinese Academy of Sciences) and were genotyped by PCR analysis of genomic DNA. All animal experiments were conducted in compliance with National Institutes of Health guidelines and were approved by the institutional animal care and use committee of the Shanghai Institutes for 
Biological Sciences (Chinese Academy of Sciences). Male and female mice were 6-12 weeks old unless otherwise indicated.

Antibodies and reagents. The following monoclonal antibodies were used for flow cytometry (1:150). Anti-CD4 (RM4-5), anti-CD8 $\alpha$ (53-6.7), anti-CD44 (IM-7), anti-CD62L (MEL-14), anti-CD122 (5H4), anti-CD69 (H1.2F3), antiCD25 (PC61), anti-IFN $\gamma$ (XMG1.2) and anti-IL-2 (JES6-5H4) were purchased from BD Pharmingen. Anti-TNF $\alpha$ (MP6-XT22), anti-granzyme B (GB11), APC Annexin V and FITC Annexin V reagents $\left(5 \mu \mathrm{l}\right.$ per $10^{5}$ cells) were purchased from Biolegend. The anti-perforin (eBio0MAK-D) antibody was purchased from eBioscience. The anti-Pol II (N-20) and normal rabbit IgG antibodies used in the ChIP assays ( $4 \mu \mathrm{g}$ per sample) were obtained from Santa Cruz Biotechnology. The anti-CD3 (145-2C11) and anti-CD28 (37.51) antibodies used for in vitro stimulation $\left(1 \mu \mathrm{g} \mathrm{ml}^{-1}\right.$ unless otherwise indicated) were obtained from BD Pharmingen. Anti-phospho-tyrosine (1:1,000), anti-phospho-Erk 1/2 (1:1,000), anti-phospho-Plc $\gamma 1$ (1:1,000), anti-Plc $\gamma 1$ (1:1,000), anti-phospho-Src $(1: 1,000)$, anti-phospho-Jnk $(1: 1,000)$ and anti-phospho-P38 antibodies $(1: 1,000)$ were purchased from Cell Signaling Technology. The anti-phospho-Zap70/Syk antibody (1:500) was purchased from Santa Cruz Biotechnology. PMA and ionomycin were obtained from Merck. The 5-Bromo-2'-deoxyuridine, carboxyfluorescein succinimidyl ester, collagenase IV and hyaluronidase were purchased from Sigma. The Taq Master Mix was from Vazyme Biotech. The mouse anti-dsDNA IgG-specific ELISA Kit was purchased from Alpha Diagnostic International, Inc. The mouse IFN $\gamma$ ELISA kit was obtained from Biolegend.

Cell staining and purification. Single-cell thymocyte or lymphocyte suspensions were prepared and surface stained as previously described ${ }^{47}$. Briefly, thymuses or lymph nodes were dissected from mice and single-cell suspensions were made by gently teasing with forceps and filtering over nylon. Cells were distributed in $5 \mathrm{ml}$ polystyrene round-bottom tube (Corning, Inc.), and stained for $40 \mathrm{~min}$ at $4{ }^{\circ} \mathrm{C}$ with indicated antibodies. Intracellular staining was performed after $10 \mathrm{~min}$ fixation $(2 \%$ formaldehyde PBS) at room temperature and 5 min permeabilization in IC staining buffer ( $0.1 \%$ saponin, $0.1 \%$ bovine serum albumin Hank's balanced salt solution) at $4{ }^{\circ} \mathrm{C}$. Cell fluorescence was determined using a two-laser FACSCalibur (BD Biosciences) flow cytometer, and data were analysed with FlowJo software (TreeStar, Inc., Olten, Switzerland). Naive $\mathrm{CD} 4^{+}$or $\mathrm{CD} 8{ }^{+} \mathrm{T}$ cells were sorted using a FACSAria II cell sorter (BD Biosciences), and the cell purity was consistently greater than $90 \%$. For ChIP assays and lentivirus transduction, naïve $\mathrm{CD} 4{ }^{+} \mathrm{T}$ cells were purified using a mouse naive $\mathrm{CD} 4{ }^{+} \mathrm{T}$ cell isolation kit (Stem Cell Technology). Tumour- or tissue-infiltrating leukocytes were fractionated from tumours or the indicated organs and digested with $160 \mu \mathrm{g} \mathrm{ml}^{-1}$ collagenase IV and $100 \mu \mathrm{g} \mathrm{ml}^{-1}$ hyaluronidase at $37^{\circ} \mathrm{C}$ for $90 \mathrm{~min}$. Discontinuous $40-80 \%(\mathrm{v} / \mathrm{v})$ percoll gradients were used for density fractionation.

Adoptive transfer. A total of $10^{6}$ naive $\mathrm{T}$ cells from CD45.1 ${ }^{+} \mathrm{WT}$ and $\mathrm{Med} 23^{-1-}$ mice were suspended in $150 \mu \mathrm{l}$ PBS and injected intravenously into the dorsal tail vein of mice deficient in recombination-activating gene 1 at 10 weeks of age. Six days after transfer, the expressions of CD62L and CD44 on splenic T cells were analysed by flow cytometry.

T-cell stimulation. TCR cross-linking was performed as previously described ${ }^{48}$. In brief, cells were coated for $10 \mathrm{~min}$ at $4{ }^{\circ} \mathrm{C}$ with biotinylated anti-TCR $\beta$ and anti-CD4, cross-linked with strepavidin and processed for western blot (full blots can be found in Supplementary Fig. 8). Intracellular staining was performed after the cells were stimulated with PMA and ionomycin for $4 \mathrm{~h}$ in the presence of brefeldin A. Naïve T cells were stimulated in vitro through plate-bound antibodies. Cell culture plates were coated with anti-CD3 and anti-CD28 in PBS at $4{ }^{\circ} \mathrm{C}$ overnight.

PyMT tumour development. PyMT Med $23^{-1-}$ and PyMT WT mice were examined by visual inspection and palpation every 2-3 days to monitor tumour onset. The tumour size was measured weekly with digital vernier calipers and the tumour volume was estimated using the formula $A \times B^{2} / 2$, where $A$ is the sagittal dimension $(\mathrm{mm})$ and $B$ is the cross dimension $(\mathrm{mm})$.

Histology staining. Perfused lungs, livers and mammary tumours from killed mice were dissected, fixed in $4 \%(\mathrm{v} / \mathrm{v})$ buffered neutral formalin and embedded in paraffin. Five-micron tissue sections were stained with haematoxylin and eosin. All images were acquired with an Olympus BX51 microscope and DP71 camera (Olympus).

Real-time reverse transcriptase-PCR. Total RNA was extracted with TRIzol (Invitrogen), and RNA was reverse-transcribed using the SuperScript III First-Strand kit (Invitrogen). The mRNA levels of the indicated genes were assessed relative to GAPDH using real-time PCR (Rotor gene 6000; Corbett Life Sciences) with a SYBR Green QPCR Master Mix (Toyobo). The following primers were used for qPCR: Egrl, 5'-GAACAACCCTATGAGCACCTGAC-3' and 5'-CGAGTCGTT
TGGCTGGGATA-3'; Egr $2,5^{\prime}$-CCTTTGACCAGATGAACGGAGTG- ${ }^{\prime}$ and $5^{\prime}$-CTGGTTTCTAGGTGCAGAGATGG- $3^{\prime} ;$ Klf2, $5^{\prime}$-AGCCTATCTTGCCG TCCTTT- $3^{\prime}$ and $5^{\prime}$-CGCCTCGGGTTCATTTC- $3^{\prime}$; Foxp $15^{\prime}$-GCACCTTCCAAG TCCTCC- $3^{\prime}$ and $5^{\prime}$-GTCACAAACCGCCTCACA- $3^{\prime}$.

ChIP assay. Purified naive T cells were cultured for $4 \mathrm{~h}$ in a 24 -well plate that was precoated with anti-CD3 and anti-CD28 or vehicle at $4{ }^{\circ} \mathrm{C}$ overnight. ChIP assays were then performed based on the manufacturer's instructions, with modifications (Upstate Biology). Stimulated and unstimulated naïve T cells were cross-linked for 30 min on ice with $1 \%(\mathrm{v} / \mathrm{v})$ formaldehyde and lysed for $10 \mathrm{~min}$ on ice. The lysates were sonicated to obtain DNA fragments with an average length of $500 \mathrm{bp}$. The fragmented lysates were subjected to IP with the indicated antibodies. The recovered DNA was used as templates for real-time PCR quantification. The following primers were used for qPCR: Egr1, 5'-CGTGCTGTTCCAGACCCTTG-3' and $5^{\prime}$-GCTGGGATCTCTCGCGACTC-3'; Egr 2 , 5' -GGAGAGAGTCAGTGA CGGATAGAC- $3^{\prime}$ and $5^{\prime}$-GAACTGAGCCTAGGATGGTATCTC- $3^{\prime}$; Klf2, $5^{\prime}$-GCGCCTATAAGGCCTGGGTGGG- $3^{\prime}$ and $5^{\prime}$-AAGTGGCAAAGGACGGCAA GAT-3'; Foxp 1, 5'-CGCCTGATTGAGCCAGTTGT-3' and 5'-CGGCAGTGTGAG GAAGGACT- $3^{\prime}$.

Lentivirus transduction. 293FT cells were transfected with pHAGE-fEFla-IRESZsGreen or the indicated plasmids. The lentiviral supernatants were collected from cultured media $48-60 \mathrm{~h}$ after transfection. Naïve $\mathrm{CD} 4^{+} \mathrm{T}$ cells were incubated in media containing $50 \%$ lentiviral supernatants. After $24 \mathrm{~h}$, half of the culture medium was replaced with fresh lentiviral supernatant, and cells were used for the indicated experiments after $48 \mathrm{~h}$.

Statistical analysis. All data were expressed as mean \pm s.e.m. The tumour-free curve was analysed using the log-rank (Mantel-Cox) test. The two-tailed Student's $t$-test was used for the comparison of two independent groups. $P$-values $<0.05$ were considered statistically significant. Randomization and blinding strategy was used whenever possible. Sample size was calculated using variance from previous experiments to indicate power, with statistical significance set at $95 \%$.

\section{References}

1. Chambers, C. A. The expanding world of co-stimulation: the two-signal model revisited. Trends Immunol. 22, 217-223 (2001).

2. Risso, A. et al. CD69 in resting and activated T lymphocytes. Its association with a GTP binding protein and biochemical requirements for its expression. J. Immunol. 146, 4105-4114 (1991).

3. Grossman, Z. \& Paul, W. E. Autoreactivity, dynamic tuning and selectivity. Curr. Opin. Immunol. 13, 687-698 (2001).

4. Smith-Garvin, J. E., Koretzky, G. A. \& Jordan, M. S. T cell activation. Annu. Rev. Immunol. 27, 591-619 (2009).

5. Hermiston, M. L., Xu, Z. \& Weiss, A. CD45: a critical regulator of signaling thresholds in immune cells. Annu. Rev. Immunol. 21, 107-137 (2003).

6. Stefanova, I. et al. TCR ligand discrimination is enforced by competing ERK positive and SHP-1 negative feedback pathways. Nat. Immunol. 4, 248-254 (2003).

7. Bachmaier, K. et al. Negative regulation of lymphocyte activation and autoimmunity by the molecular adaptor Cbl-b. Nature 403, 211-216 (2000).

8. Naramura, M. et al. c-Cbl and Cbl-b regulate T cell responsiveness by promoting ligand-induced TCR down-modulation. Nat. Immunol. 3, 1192-1199 (2002).

9. Viola, A. \& Lanzavecchia, A. T cell activation determined by T cell receptor number and tunable thresholds. Science 273, 104-106 (1996).

10. Zhang, W., Sloan-Lancaster, J., Kitchen, J., Trible, R. P. \& Samelson, L. E. LAT: the ZAP-70 tyrosine kinase substrate that links T cell receptor to cellular activation. Cell 92, 83-92 (1998).

11. Zhao, H. et al. A novel E3 ubiquitin ligase TRAC-1 positively regulates $\mathrm{T}$ cell activation. J. Immunol. 174, 5288-5297 (2005).

12. Wang, Z., Kim, J. I., Frilot, N. \& Daaka, Y. Dynamin2 S-nitrosylation regulates adenovirus type 5 infection of epithelial cells. J. Gen. Virol. 93, 2109-2117 (2012).

13. Wang, C. et al. Actin-bundling protein L-plastin regulates T cell activation. J. Immunol. 185, 7487-7497 (2010).

14. Liu, J. O. The yins of T cell activation. Sci. STKE 2005, re1 (2005).

15. Parry, R. V. et al. CTLA-4 and PD-1 receptors inhibit T-cell activation by distinct mechanisms. Mol. Cell. Biol. 25, 9543-9553 (2005).

16. Waterhouse, P. et al. Lymphoproliferative disorders with early lethality in mice deficient in Ctla-4. Science 270, 985-988 (1995).

17. Francisco, L. M., Sage, P. T. \& Sharpe, A. H. The PD-1 pathway in tolerance and autoimmunity. Immunol. Rev. 236, 219-242 (2010).

18. Schmidt, A., Oberle, N. \& Krammer, P. H. Molecular mechanisms of treg-mediated T cell suppression. Front. Immunol. 3, 51 (2012).

19. Ohashi, P. S. T-cell signalling and autoimmunity: molecular mechanisms of disease. Nat. Rev. Immunol. 2, 427-438 (2002). 
20. von Boehmer, H. \& Daniel, C. Therapeutic opportunities for manipulating $\mathrm{T}$ (Reg) cells in autoimmunity and cancer. Nat. Rev. Drug Discov. 12, 51-63 (2013).

21. Lewis, B. A. \& Reinberg, D. The mediator coactivator complex: functional and physical roles in transcriptional regulation. J. Cell. Sci. 116, 3667-3675 (2003).

22. Malik, S. \& Roeder, R. G. Dynamic regulation of pol II transcription by the mammalian Mediator complex. Trends Biochem. Sci. 30, 256-263 (2005).

23. Malik, S. \& Roeder, R. G. The metazoan mediator co-activator complex as an integrative hub for transcriptional regulation. Nat. Rev. Genet. 11, 761-772 (2010).

24. Stevens, J. L., Cantin, G. T., Wang, G., Shevchenko, A. \& Berk, A. J. Transcription control by E1A and MAP kinase pathway via Sur2 mediator subunit. Science 296, 755-758 (2002).

25. Wang, G. et al. Mediator requirement for both recruitment and postrecruitment steps in transcription initiation. Mol. Cell 17, 683-694 (2005).

26. Wang, W. et al. Mediator MED23 links insulin signaling to the adipogenesis transcription cascade. Dev. Cell 16, 764-771 (2009).

27. Hashimoto, S. et al. MED23 mutation links intellectual disability to dysregulation of immediate early gene expression. Science 333, 1161-1163 (2011).

28. Yin, J. W. et al. Mediator MED23 plays opposing roles in directing smooth muscle cell and adipocyte differentiation. Genes Dev. 26, 2192-2205 (2012).

29. Yang, X. et al. Selective requirement for Mediator MED23 in Ras-active lung cancer. Proc. Natl Acad. Sci. USA 109, E2813-E2822 (2012).

30. Takada, K. \& Jameson, S. C. Naive T cell homeostasis: from awareness of space to a sense of place. Nat. Rev. Immunol. 9, 823-832 (2009).

31. Boyman, O., Cho, J. H., Tan, J. T., Surh, C. D. \& Sprent, J. A major histocompatibility complex class I-dependent subset of memory phenotype CD8 + cells. J. Exp. Med. 203, 1817-1825 (2006).

32. Forster, I. \& Lieberam, I. Peripheral tolerance of CD4 T cells following local activation in adolescent mice. Eur. J. Immunol. 26, 3194-3202 (1996).

33. Feng, X. et al. Transcription factor Foxp1 exerts essential cell-intrinsic regulation of the quiescence of naive T cells. Nat. Immunol. 12, 544-550 (2011).

34. Kuo, C. T., Veselits, M. L. \& Leiden, J. M. LKLF: a transcriptional regulator of single-positive T cell quiescence and survival. Science 277, 1986-1990 (1997).

35. Buckley, A. F., Kuo, C. T. \& Leiden, J. M. Transcription factor LKLF is sufficient to program T cell quiescence via a c-Myc-dependent pathway. Nat. Immunol. 2, 698-704 (2001).

36. Safford, M. et al. Egr-2 and Egr-3 are negative regulators of T cell activation. Nat. Immunol. 6, 472-480 (2005).

37. Zhu, B. et al. Early growth response gene 2 (Egr-2) controls the self-tolerance of $\mathrm{T}$ cells and prevents the development of lupuslike autoimmune disease. J. Exp. Med. 205, 2295-2307 (2008).

38. Guy, C. T., Cardiff, R. D. \& Muller, W. J. Induction of mammary tumors by expression of polyomavirus middle $\mathrm{T}$ oncogene: a transgenic mouse model for metastatic disease. Mol. Cell. Biol. 12, 954-961 (1992).

39. Rudd, C. E. \& Schneider, H. Lymphocyte signaling: Cbl sets the threshold for autoimmunity. Curr. Biol. 10, R344-R347 (2000).

40. Collins, S. et al. Opposing regulation of T cell function by Egr-1/NAB2 and Egr-2/Egr-3. Eur. J. Immunol. 38, 528-536 (2008).
41. Grossman, Z. \& Paul, W. E. Adaptive cellular interactions in the immune system: the tunable activation threshold and the significance of subthreshold responses. Proc. Natl Acad. Sci. USA 89, 10365-10369 (1992).

42. Lovatt, M. et al. Lck regulates the threshold of activation in primary $\mathrm{T}$ cells, while both Lck and Fyn contribute to the magnitude of the extracellular signalrelated kinase response. Mol. Cell. Biol. 26, 8655-8665 (2006).

43. Kim, E. Y. \& Teh, H. S. TNF type 2 receptor (p75) lowers the threshold of T cell activation. J. Immunol. 167, 6812-6820 (2001).

44. Bachmann, M. F., Barner, M. \& Kopf, M. CD2 sets quantitative thresholds in T cell activation. J. Exp. Med. 190, 1383-1392 (1999).

45. Avitahl, N. et al. Ikaros sets thresholds for T cell activation and regulates chromosome propagation. Immunity 10, 333-343 (1999).

46. Cao, Y. et al. LKB1 regulates TCR-mediated PLCgammal activation and thymocyte positive selection. EMBO J. 30, 2083-2093 (2011).

47. Wang, X. et al. Regulation of Tcrb recombination ordering by c-Fos-dependent RAG deposition. Nat. Immunol. 9, 794-801 (2008).

48. Liu, X. et al. Restricting Zap70 expression to CD4 + CD8 + thymocytes reveals a $\mathrm{T}$ cell receptor-dependent proofreading mechanism controlling the completion of positive selection. J. Exp. Med. 197, 363-373 (2003).

\section{Acknowledgements}

We are grateful to our colleagues $\mathrm{H}$. Chen for animal husbandry and W. Bian for cell sorting. This work was supported by National Basic Research Program of China (2013CB835300 and 2012CB518700), National Natural Science Foundation of China (31270936 and 81261120380) and Shanghai Municipal Government Grant $12 \mathrm{XD} 1405800$.

\section{Author contributions}

Y.S., X.Z. and X.L. designed the experiments, analysed the data and prepared the manuscript; Y.S., X.Z., X.C., H.L., Y.X. and Y.C. performed experiments; G.W. provided materials and helpful discussion; X.L. conceptualized the research and directed the study.

\section{Additional information}

Accession codes: Microarray data have been deposited in the Gene Expression Omnibus database under accession code GSE60779.

Supplementary Information accompanies this paper at http://www.nature.com/ naturecommunications

Competing financial interests: The authors declare no competing financial interests.

Reprints and permission information is available online at http://npg.nature.com/ reprintsandpermissions/

How to cite this article: Sun, Y. et al. The mediator subunit Med23 contributes to controlling T-cell activation and prevents autoimmunity. Nat. Commun. 5:5225 doi: $10.1038 /$ ncomms6225 (2014). 